\title{
Insights on the Human Amniotic Membrane in Clinical Practice with a Focus on the New Applications in Retinal Surgery
}

\author{
Ruggero Tartaro ${ }^{1}$ (D) Tomaso Caporossi $^{1} \cdot$ Gianni Virgili $^{1} \cdot$ Francesco Barca $^{1} \cdot$ Fabrizio Giansanti $^{1} \cdot$ Stanislao Rizzo $^{2}$
}

Received: 27 July 2020 / Revised: 7 November 2020 / Accepted: 17 November 2020 / Published online: 14 December 2020

(C) The Author(s) 2020

\section{Lay Summary}

Recently, the use of the human amniotic membrane (hAM) has been extended to treat retinal disorders such as refractory macular holes, retinal breaks and dry and wet age-related macular degeneration. Not only the hAM has proved to be an excellent tool for repairing retinal tissue, but it has also shown a promising regeneration potential. This review aims to highlight the novel use of the $\mathrm{hAM}$ in treating retinal diseases. Although the hAM has been used in the ocular anterior segment reconstruction for more than 60 years, in the last 2 years, we have found in literature articles showing the use of the hAM in the retinal surgery field with interesting results in terms of tissue healing and photoreceptor regeneration.

Keywords Human amniotic membrane $\cdot$ Retinal regeneration $\cdot$ Nerve regeneration $\cdot$ Post-stroke recovery $\cdot$ Corneal regeneration

\section{Introduction}

Retinal diseases such as refractory macular holes, agerelated macular degeneration and retinal detachment are characterized by a permanent loss of a large part of the photoreceptors. In recent years, vitreoretinal surgeons have proposed numerous procedures and substances to induce a regeneration of the retinal layers and, especially, the photoreceptor layers.

Recently, Prof Rizzo, Dr. Caporossi, et al. published a group of articles on the use of the human amniotic membrane (hAM) to repair refractory macular holes or peripheral retinal tears ([1]). Not only have they proved that the human amniotic membrane (hAM) is an excellent tool for repairing retinal tissue, but they also have shown that it can induce a regeneration of the retinal layers. The authors have shown optical coherence tomography (OCT) images indicating a regeneration of

Ruggero Tartaro

ruggerotartaro@yahoo.it

1 Dipartimento organo-muscolo-scheletrico e organi di sensi, Azienda Ospedaliera Universitaria Careggi, Florence, Italy

2 Universita' Cattolica del Sacro Cuore, IRCCS, Ospedale Agostino Gemelli, Rome, Italy the retinal layers (Fig. 1) with a cellular migration that occurred above the amniotic membrane (Fig. 2). The authors demonstrated a visual acuity improvement in almost all patients.

Moreover, the authors extended the use of hAM in other retinal pathologies such as myopic macular holes associated with retinal detachment [2] and dry and wet age-related macular degeneration [3]. Prof Rizzo and Dr. Caporossi's group have proposed, for the first time, the use of the hAM to treat these pathologies. The purpose of this review is to report all the scientific evidence that has induced Prof Rizzo and Dr. Caporossi to apply the hAM graft in retinal pathologies.

The hAM is non-immunogenic [4], contains high levels of regenerative growth factors [5] and has anti-inflammatory and antiangiogenic properties [6].

Placental transplants have been used in surgical practice due to their biochemical properties and bio-architectural structure.

The hAM is the innermost layer of the placenta, and it is also called amnion. The hAM is a semipermeable avascular layer characterized by nerves, lymphatic tissue and matrix containing cytokines, enzymes and other active molecules. The hAM is translucid, $0.02-0.05-\mathrm{mm}$ thick and made up of an epithelium: cuboidal cells with abundant microvilli and active metabolism, a basement membrane composed of IV and VII collagen, laminin, 


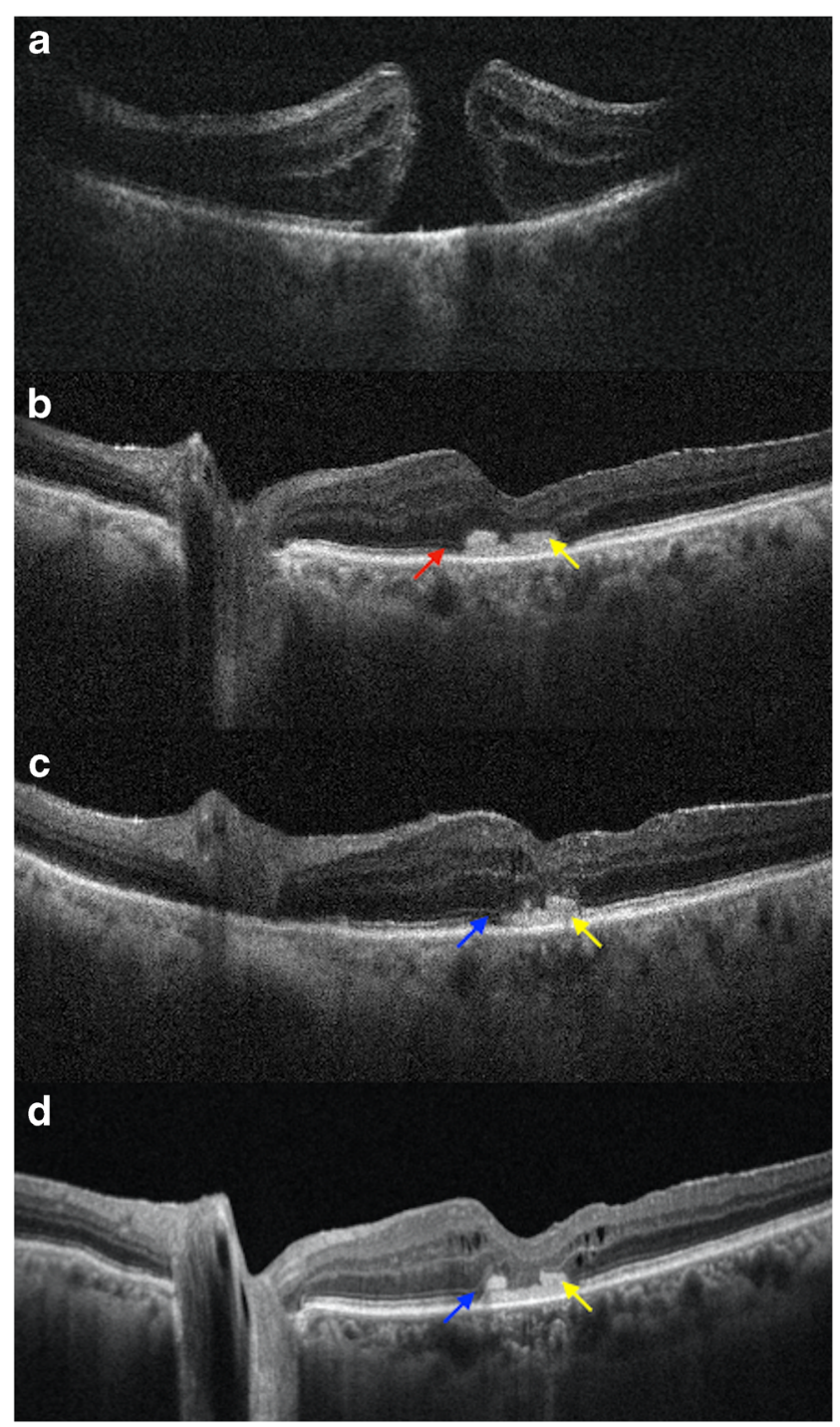

Fig. 1 Preoperative OCT showing a macular hole that failed to close, with an already peeled ILM (A). Three months postoperative OCT showing the macular hole closure. The regenerative process of the external retinal layers is starting (red arrow) (1B). Six months OCT (1C) and 12-month OCT (1D), the regeneration of the external retinal layers progressed (red arrows) and we cannot observe any sign of rejection. The amniotic membrane partially dissolved after 1 year (yellow arrow)

fibronectin, hyaluronic acid and an avascular stroma [7-9]. The hAM can produce a wide variety of growth factors such as transforming growth factor (TGF $\alpha$, TGF $\beta-1, \beta-2$ and $\beta-3)$, basic fibroblast growth factor, the epithelial growth factor, hepatocyte growth factor and its receptor and keratinocyte growth factor and its receptor [10-15]. Surgically implanted hAM wraps, furthermore, are a reservoir of neurotrophic factors as nerve growth factor (NGF), brain-derived neurotrophic factor (BDNF), neurotrophin 3 (NT-3), glial cell-derived neurotrophic factor (GDNF) and ciliary neurotrophic factor (CNTF) $[16,17]$.

\section{Human Amniotic Membrane Cells in Nervous Tissue and Neuronal Regeneration}

It has been demonstrated that hAM cells can differentiate in neural cells in vivo and in vitro [18]. Moreover, the expression of glial cell-derived neurotrophic factor (AF-GDNF), secreted by the hAM cells, can determine a neuroprotective effect [19].

Studies, conducted in the animal model, have shown that the hAM can regenerate small, surgically sectioned, nerves $[20,21]$.

Riccio et al. applied a hAM graft wrapping in five human patients with a median nerve injury and showed promising results $[22,23]$.

Amnion epithelium produces brain natriuretic peptides and hormones that release corticotropin, a cell proliferation promoter [24].

Human amniotic epithelial cells (hAECs) can be obtained from the epithelial sheet of the amnion, which are immediately available and a relatively economical reservoir of cells for clinical application.

hAECs are foetal in principle and therefore exhibit a high level of pluripotency. Contrarily to other stem cell lineages, hAECs are readily available and do not require invasive harvesting procedures. hAECs are immunologically inert due to the low surface expression of human leukocyte antigens (HLA)-A, HLA-B, HLA-C and HLA$\mathrm{DR}$, which are critically implicated in the post-transplant rejection $[25,26]$. Conversely, hAECs express and deliver the non-polymorphic, non-classical antigen, HLA-G, which is capable of repressing immune responses. Furthermore, hAECs do not form neoplasia in vivo and do not differentiate into fibroblasts $[25,26]$. The nonimmunogenicity characteristics of the hAM suggest that they are safer than many other stem cells. In the animal model, hAECs have shown regenerative and protective potentials after an experimentally induced stroke [27].

A group of researchers [28] have enrolled a Phase I clinical trial to determine the maximum tolerable dose of hAECs in human ischemic stroke patients (Australian New Zealand Clinical Trials Registry: ACTRN12618000076279p; [26]). Gong et al. [29] showed that hAMSCs can differentiate into Schwann-like cells, with the proper chemical mediators' administration in vitro, and a considerable quantity of promoting nerve growth factors are released during the differentiation process.

HAECs have been used in the animal model with good results concerning the physical recovery in traumatic cerebral injuries [30, 31], hypoxic-ischemic injury [32] and ballisticlike brain injury [33].

HAECs can modulate the local inflammation favouring a protective/pro-regenerative environment in the damaged brain. This may produce an improvement in the neurological function. 


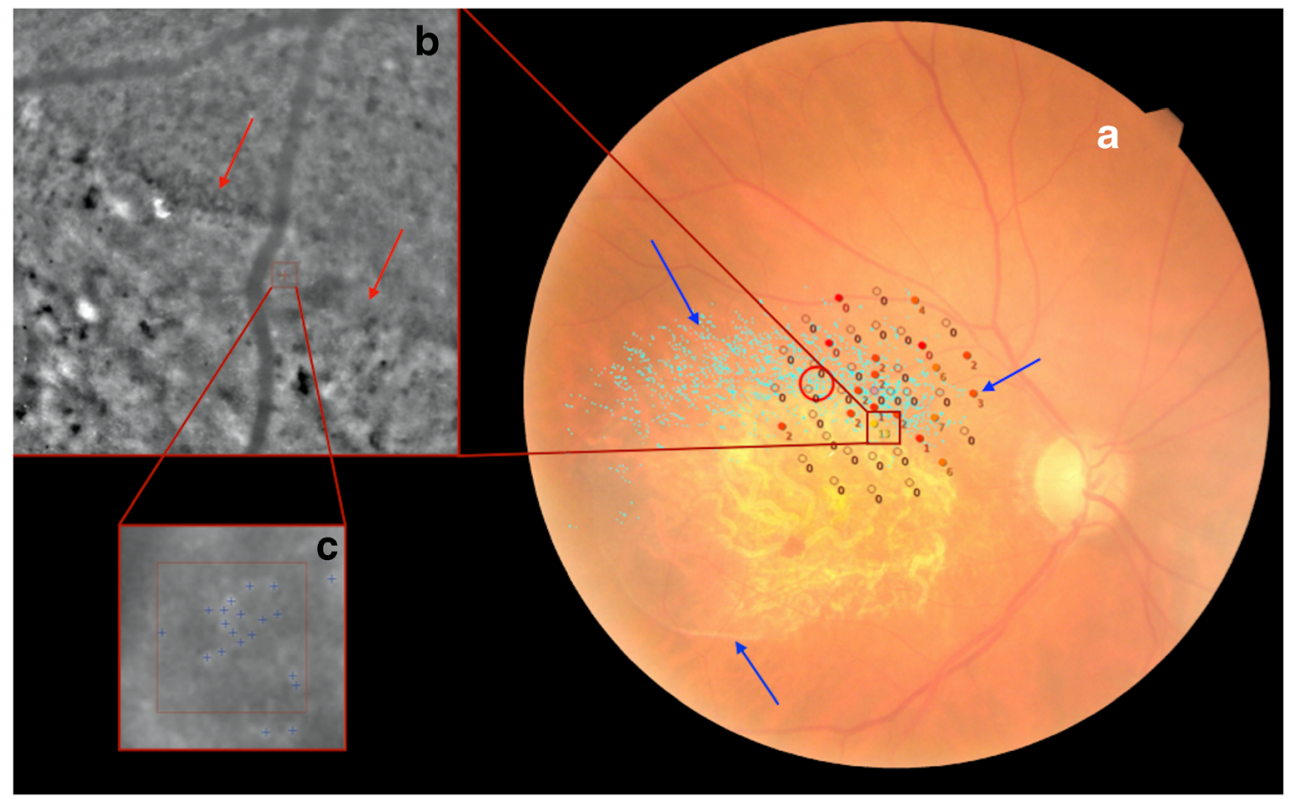

Fig. 2 Microperimetry (A) of a patient treated using choroidal neovascularisation removal and subretinal amniotic membrane implant. We can observe the amniotic membrane disc edges (blue arrows), a stable fixation at the superior edge of the amniotic membrane disc (blue dots) and the microperimetric numeric values (red dots with numbers). The adaptive optic scan was conducted in the area represented by the red square (B); we can observe the amniotic membrane edges (red arrows) and a magnified image showing the photoreceptors cells, calculated using the in-built software (Imagine eyes Rx, France) (C)
We can observe that both hAM wraps, sheets and HAECs can induce a regeneration in the neuronal tissue. It is clear that, when the target tissue is more accessible, such as a nerve, it is easier to use sheets or wraps. On the other hand, when a brain suffers from a stroke, we need to use HAECs, because this tissue is not accessible for a hAM implantation.

\section{Human Amniotic Membrane in Other Surgical Specialities}

Amnion epithelial and mesenchymal cells are pluripotent stem cells which have the ability to differentiate into all three germ layers. Amniotic cells also secrete growth factors, antiinflammatory and anti-bacterial agents which create a synergic environment for tissue healing.

The hAM controls the scarring formation through the reduction of fibrosis [34]. This effect is achieved by the downregulation of TGF-b and its receptor expression [35]. The hAM has been used in different surgical subspecialties; it can be used as a dressing or as a transplanted graft.

One of the most modern advances in wound therapy is the use of hAM transplantation for the treatment of acute and chronic skin injuries. An artificial dehydrated human amnion/chorion membrane allograft (dHACM, EpiFix; MiMedx Group, Marietta, GA) was used to treat a refractory ulcer in a 10-month-old girl, affected by a facial hemangioma [36].

EpiFix® is a cellular amniotic sheath allograft that carries many growth factors, cytokines and extracellular matrix proteins already in amniotic tissue. Moreover, it contains plateletderived growth factor (PDGF) and more than 50 growth factors, cytokines and chemokines [37]. Epifix ${ }^{\circledR}$ was also used for cutaneous ulcers such as scalp ulcers [38], burns [39], gastric ulcers [40], venous leg ulcers [41] and diabetic foot ulcers $[42,43]$.

The amniotic membrane is histologically similar to cutaneous and nervous tissue; in fact, it arises from the embryonic ectoderm. Moreover, its transparency, which offers the possibility to surveil scar formation, is very useful in the tissue regeneration field. In addition, the amniotic membrane has other interesting properties such as the capacity of decreasing exudation and wound infection, and it also accelerates epithelial regeneration, has analgesic properties, decreases heat loss and reduces scar tissue formation [44].

Swim et al. [45] created an amnion-derived scaffold to repair arteries. They obtained multi-layered compositions characterized by in vitro biocompatibility with smooth muscle cells, endothelial cells, cardiac myocytes and thymus and cord-blood-derived mesenchymal stem cells. When applied in a piglet model of left pulmonary artery graft, the multilayered sheet showed its in vivo biocompatibility and its usefulness for vascular reconstruction, as demonstrated by the generation of a newly developed endothelium in the intima, 
a smooth muscle cell-rich intermediate layer and an adventitia including new vasa vasorum [45].

Moreover, it has been demonstrated that the hAM acts as a biological dressing, accelerating re-epithelialization and preventing invasive bacterial infection in burn injuries [46].

The hAM was used in dogs as a pericardial coverage to reduce post-surgical adhesion [47], and it elicited insignificant host to graft response due to its low immunogenicity. Preliminary results, in the animal model, have advised that the AM grafts may be a safe and useful method for restricting continued air leakage from the pleura after thoracic surgery [48].

\section{Amniotic Membrane in Ocular Anterior Segment Treatments}

The AM is an excellent substrate and acts as a scaffold for tissue reconstruction, supporting the germination of corneal epithelial progenitor cells by increasing their lifespan, supporting their clonogenicity and limiting epithelial cell apoptosis [49]. The hAM has an anti-inflammatory effect which is achieved through the secretion inhibition of a wide range of mediators, such as the interferon (IFN), bFGF, interleukin (IL)-1,TNF-b and plateletderived growth factor (PDGF) on the damaged corneal and conjunctival surface $[50,51]$. Its stromal matrix can induce apoptosis in inflammatory cells and contains several forms of protease inhibitors [52-54]. These properties of the AM may reduce scars and inflammation after its transplantation.

The structural integrity, transparency and elasticity of the amniotic basement membrane make it a widely accepted tissue replacement for ocular surface reconstruction.

The use of amniotic membrane transplantation to treat ocular surface abnormalities was first reported in 1940 as a graft for conjunctival surface reconstruction [55]. Later, it has been used for treating acute ocular caustic burns [56]. After these experiences, the use of amniotic membrane disappeared from the literature until 1995, when Kim and Tseng reported a study which described a rabbit cornea reconstruction [57]. The interest in this procedure has grown after the improvements in the methods of processing and preserving the hAM, and so the possibility of maintaining its inherent properties [53].

In most recent years, it has been demonstrated that the human amniotic membrane can be successfully used in the treatment of persistent corneal epithelial lesions [58-60], corneal ulcerations [59, 61, 62], symptomatic bullous keratopathy [63], band keratopathy [64], chemical and thermal burns $[65,66]$, recurrent pterygium $[67,68]$, ocular cicatricial pemphigoid and Stevens-Johnson syndrome [69]. In these cases, the hAM worked as an optimal biological support for cell growth. Moreover, clinical outcomes of repeated autologous cultivated limbal epithelial cells' transplantation for ocular surface burns showed that the hAM is a useful promoter for stem cells' growth and differentiation [70,71]. In treating the ocular surface diseases, the hAM has shown remarkable reconstructive and regenerative capacities; moreover, it has demonstrated anti-inflammatory, antiangiogenic, and antimicrobial effects [53, 54, 72-77].

Many authors think that the hAM triggers the repression of conjunctival fibrosis, the reduction of inflammatory cytokines, the epithelialization promotion and the suppression of protease activity [78], although the specific regulatory mechanisms are not entirely understood. Transplanted hAM can remain on the corneal surface for a long time without being deteriorated or assimilated, but its presence does not cause an inflammatory reaction, rejection or opacity [79].

The use of hAM in anterior segment ophthalmic surgery has gained enormous popularity, as shown by the over 700 reports by 2009 [80].

\section{Amniotic Membrane in Retinal Pathologies}

The hAM seems to be a good candidate in the treatment of retinal degenerative diseases, including age-related macular degeneration, thanks to its anti-inflammatory and antiangiogenic properties and the ability to create an excellent growth support for the host's retinal pigment epithelium (RPE) cells. Recently human RPE cells have been cultured in vitro over a hAM sheet, which has demonstrated to be a feasible substrate for growth and proliferation of the RPE. The RPE cells maintained epithelial features and constituted a highly organized monolayer [81]. Moreover, Ohno-Matsui et al. [82] have demonstrated that RPE cells cultured on a hAM sheet acquire an epithelial phenotype and secrete several growth factors necessary for maintaining the retinal homeostasis. Later, hAM was implanted into pig's subretinal space, which underwent the RPE surgical removal and a mechanical damage to the Bruch's membrane. The hAM was well tolerated, caused only limited inflammation, reduced significantly the choroidal neovascularization and was covered by a monolayer of pigmented cells in contact to the host RPE [83].

Finally, the hAM plug was used in the treatment of suprachoroidal silicone oil migration related to a choroidal hole in a traumatic globe rupture that had caused hypotony. The hAM acted as a mechanical scaffold and promoted collagen formation and choroid vascular growth, achieving the tissue regeneration 3 months postoperatively [84].

Prof Rizzo, Dr. Caporossi and colleagues [1] implanted, for the first time, in the human eyes a hAM plug under the retina to promote tissue healing and regeneration. They used a cryopreserved hAM which was contained in a solution composed of a cryoprotectant (glycerol or dimethyl sulfoxide-DMSO) and a Dulbecco's modified Eagle's medium. This type of preparation allows a 20 to $50 \%$ amniotic cell survival rate [85] and represents the current format in clinical practice and clinical trials [86]. Inside the vitreous cavity, the hAM was handled under 
Fig. 3 Postoperative OCT showing an extremely large iatrogenic macular tear $(4.78 \mathrm{~mm})$ with an amniotic membrane disc underneath. The blue arrow indicates the macular hole edges (A). The 6-month OCT showed an inward migration of the hole margins that covered the large hole. (B) The same choroidal lacuna is evidenced in both figures using a red arrow

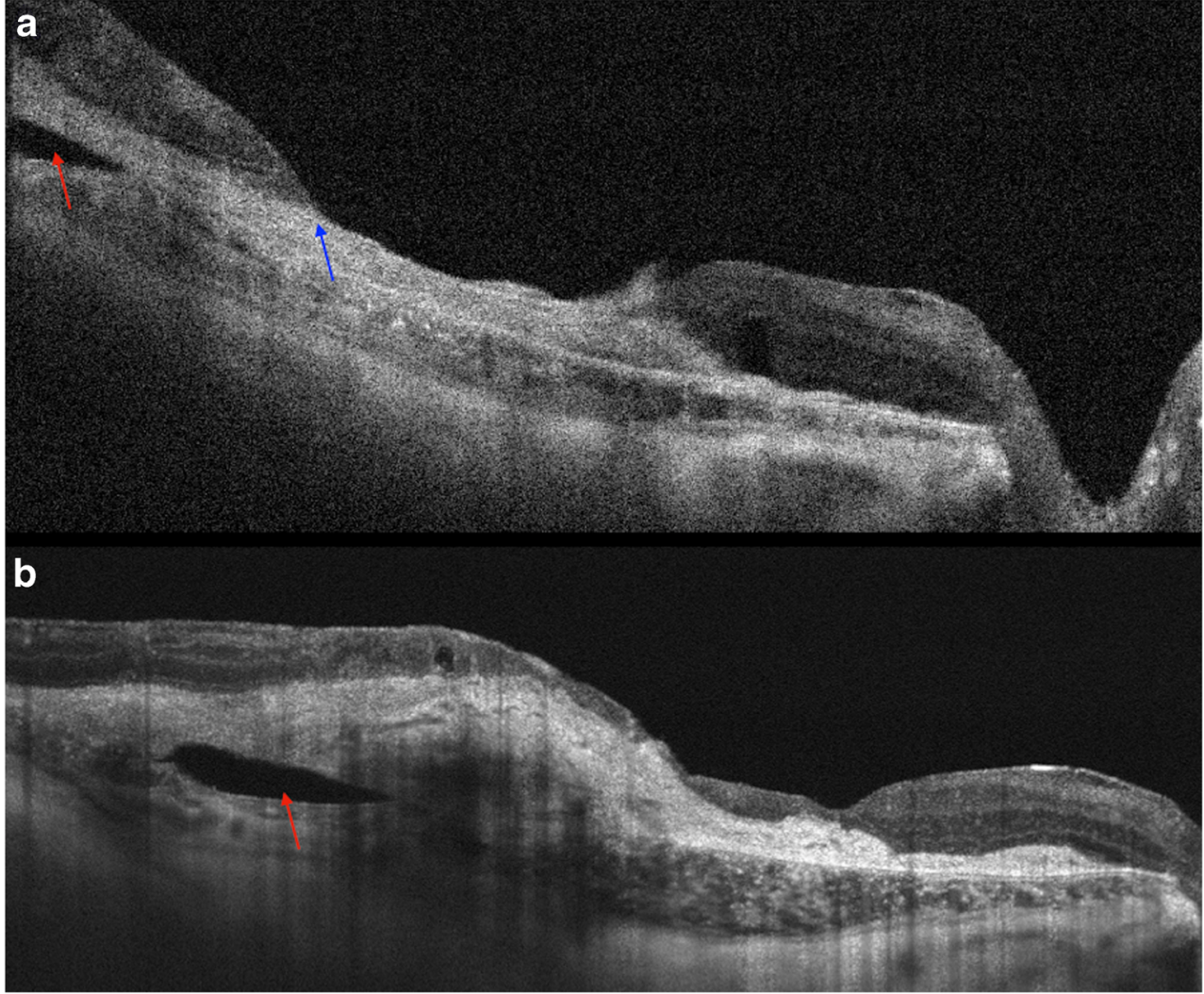

fluid and grafted through a retinal break or a macular hole into the subretinal space; it was then spread to cover the entire portion of the retinal defect. A silicone oil injection was performed at the end of the surgery. The OCT analysis revealed a retinal adhesion over the amniotic membrane plug in the macular holes or the retinal break sites during the first week after surgery. During the first 2 to 3 months, a retinal ingrowth at the retinal break's margin over the hAM plug was observed in all the cases. After the silicone oil extraction, the OCT scan revealed the retinal regeneration of the external layers over the hAM plug (Fig. 1). All the cases improved their visual acuity, except

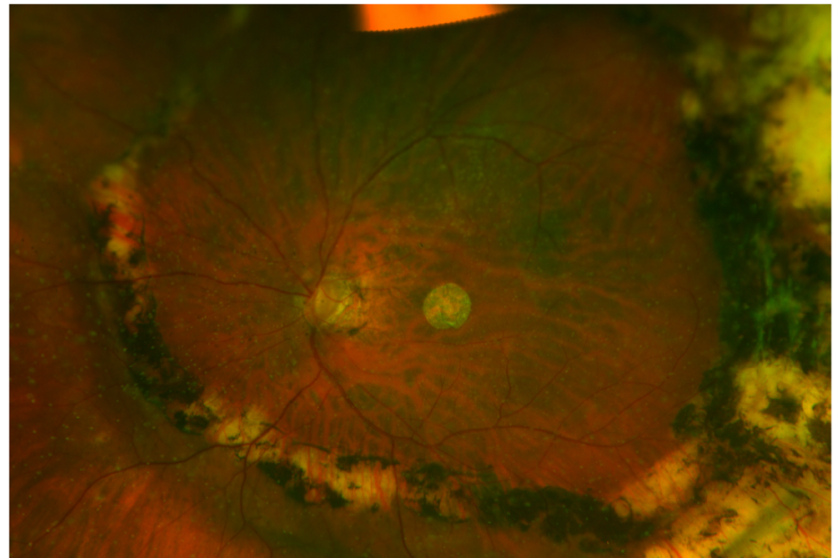

Fig. 4 A hAM successful transplant in an age-related macular degeneration case a severe macula-off rhegmatogenous retinal detachment which maintained the same low visual function. They did not observe any proliferative vitreoretinopathy or abnormal scarring. After these results, Prof Rizzo and Dr. Caporossi's group published numerous articles, extending the hAM's indications for other retinal pathologies such as myopic macular holes associated with retinal detachment [2] and chronic post traumatic macular holes [87]. Moreover, they published interesting surgical techniques, inspired by corneal surgery, for the hAM insertion [88]. The first macular holes were tamponed using silicone oil and gas because the authors were concerned about hAM's postoperative dislocation, whereas the most recent cases were tamponed with air only because they understood that the hAM plug was stable inside the macular hole in the postoperative time [89]. Prof Rizzo's group obtained interesting results, using the hAM, also in the end-stage dry and wet age-related macular degeneration treatment [3]. Not only the hAM, positioned under the retina, demonstrated its safety and non-immunogenicity, but it showed a good microperimetry function and photoreceptor cell repopulation (observed using adaptive optics technology) (Fig. 2). Age-related macular degeneration is the leading cause of blindness in the industrialized world and Prof Rizzo's group for the first time introduced the hAM in the treatment of this chronic degenerative disease. In recent times, interesting new surgical treatments have been suggested for AMD. Autologous retinal and chorioretinal transplants have been proposed by Dr. Parolini [90], and Prof. Da Cruz created 


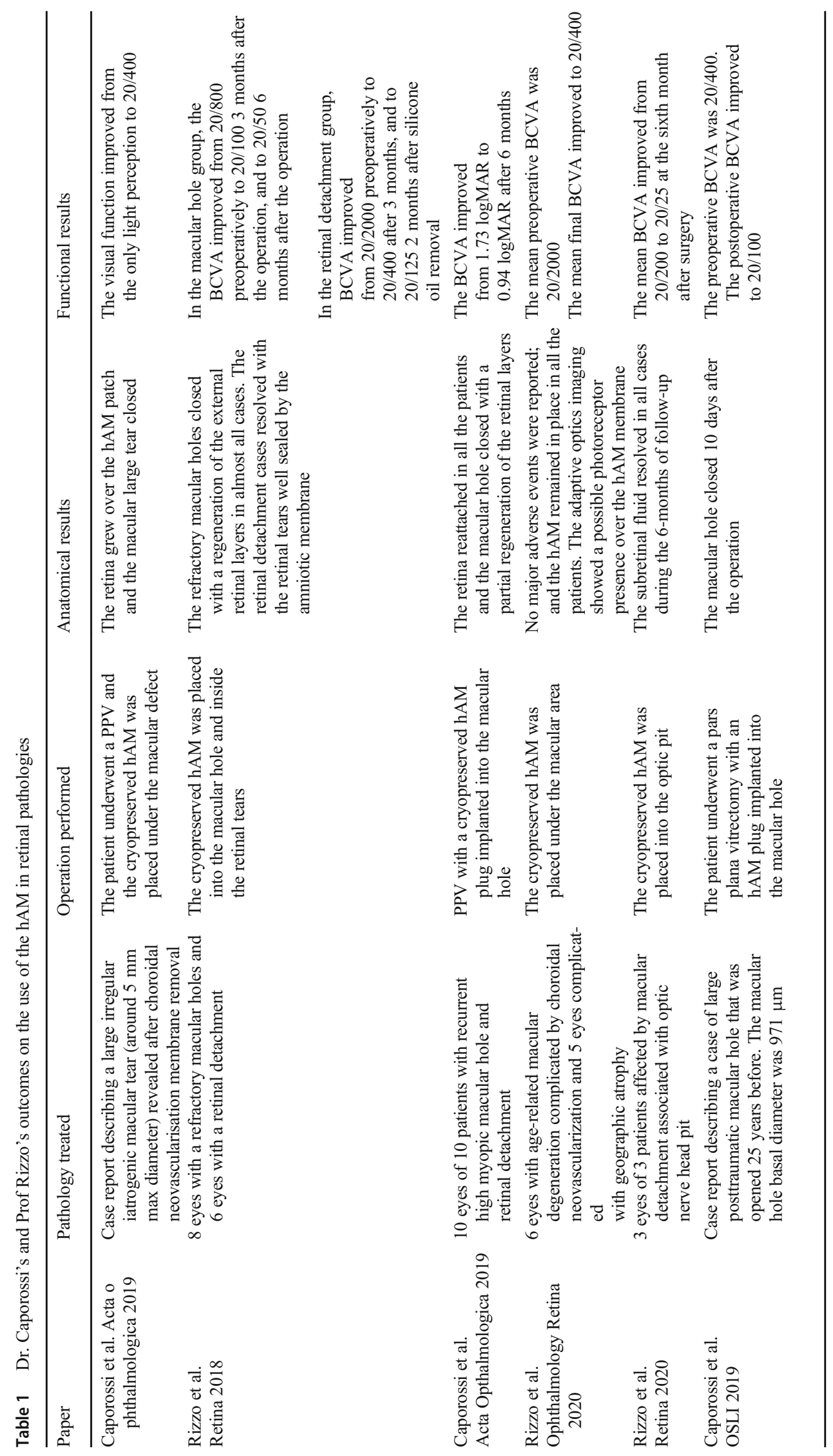


an embryonic stem cell-derived retinal pigment epithelium patch [91]. However, the autologous choroidal and retinal transplant are very challenging procedures with a high risk of complications such as retinal detachment with proliferative vitreoretinopathy, and the embryonic stem cell-derived retinal pigment epithelium patch was associated with systemic corticosteroid therapy because of the risk of immunogenic graft rejection. Prof Rizzo and Dr. Caporossi think that the combination of these new treatments with the hAM may be a step forward in the treatment of the AMD also because it has been demonstrated that the hAM can actively reduce abnormal neovascularization $[75,92]$ which complicates many inflammatory/degenerative diseases such as AMD. Finally, I would like to mention a case report involving a large iatrogenic macular hole that was repaired using a hAM sheet [93]. The patient had a near 4.78-mm-diameter iatrogenic macular hole after a choroidal neovascularization membrane removal. The amniotic membrane, positioned under the retina, triggered an inward migration of the hole margins that led to the hole closure. It is the first time that such a large macular hole closure was reported (Fig. 3). Regarding the anatomical and functional outcomes between dehydrated and cryopreserved hAM, a group of authors reported no significant differences in 17 consecutive cases of recurrent macular holes [94]. It may be interesting in the future to investigate micronized hAMs for retinal surgical cases. Micronization is a novel process to obtain amnion sheets, recently taken into consideration by several authors. Micronized amniotic membranes, although they have a reduced diameter, are still a reservoir of regenerative molecules and still represent a valid scaffold for tissue regeneration [95]. It may be interesting to publish the results of micronized hAMs in complicated retinal cases because these types of engineered hAMs have shown optimal properties with also a reduced diameter, which may be more suitable for micrometric retinal nervous tissue (Fig. 4).

\section{Conclusion}

To conclude, the hAM has several advantages: it is non-immunogenic, contains high levels of regenerative growth factors and has anti-inflammatory and antiangiogenic properties.

The hAM can be a tool for the creation of valid biomaterials to regenerate human nervous structure such as the retina and the RPE.

The use of hAM in surgery is increasingly proposed in the era of regenerative medicine. Prof Rizzo's and Dr. Caporossi's articles, in the field of macular holes, optic pit, retinal detachment and age-related macular degeneration, are cutting edge and promising. Specialists in the field of tissue regeneration should continue investing in this easily accessible technology.

Table 1 shows Dr Caporossi's and Prof Rizzo's outcomes on the use of the hAM in retinal pathologies.
Funding Open access funding provided by Università degli Studi di Firenze within the CRUI-CARE Agreement.

Open Access This article is licensed under a Creative Commons Attribution 4.0 International License, which permits use, sharing, adaptation, distribution and reproduction in any medium or format, as long as you give appropriate credit to the original author(s) and the source, provide a link to the Creative Commons licence, and indicate if changes were made. The images or other third party material in this article are included in the article's Creative Commons licence, unless indicated otherwise in a credit line to the material. If material is not included in the article's Creative Commons licence and your intended use is not permitted by statutory regulation or exceeds the permitted use, you will need to obtain permission directly from the copyright holder. To view a copy of this licence, visit http://creativecommons.org/licenses/by/4.0/.

\section{References}

1. Rizzo S, Caporossi T, Tartaro R, Finocchio L, Franco F, et al. 2019. A human amniotic membrane plug to promote retinal breaks repair and recurrent macular hole closure. Retina (Philadelphia, Pa). 39 Suppl 1:S95-103.

2. Caporossi T, De Angelis L, Pacini B, Tartaro R, Finocchio L, et al. A human amniotic membrane plug to manage high myopic macular hole associated with retinal detachment. Acta Ophthalmol. 2020;98(2):e252-6.

3. Rizzo S, Caporossi T, Tartaro R, Finocchio L, Pacini B, et al. Human amniotic membrane plug to restore age related macular degeneration photoreceptors' damage. Ophthalmol Retina. 2020.

4. Kubo M, Sonoda Y, Muramatsu R, Usui M. Immunogenicity of human amniotic membrane in experimental xenotransplantation. Invest Ophthalmol Vis Sci. 2001;42(7):1539-46.

5. Touhami A, Grueterich M, Tseng SCG. The role of NGF signaling in human limbal epithelium expanded by amniotic membrane culture. Invest Ophthalmol Vis Sci. 2002;43(4):987-94.

6. Hao Y, Ma DH, Hwang DG, Kim WS, Zhang F. Identification of antiangiogenic and anti-inflammatory proteins in human amniotic membrane. Cornea. 2000;19(3):348-52.

7. Kheirkhah A, Blanco G, Casas V, Hayashida Y, Raju VK, Tseng SCG. Surgical strategies for fornix reconstruction based on symblepharon severity. Am J Ophthalmol. 2008;146(2):266-75.

8. Li W, He H, Chen Y-T, Hayashida Y, Tseng SCG. Reversal of myofibroblasts by amniotic membrane stromal extract. J Cell Physiol. 2008;215(3):657-64.

9. Tosi GM, Massaro-Giordano M, Caporossi A, Toti P. Amniotic membrane transplantation in ocular surface disorders. J Cell Physiol. 2005;202(3):849-51.

10. Heerema-McKenney A. Defense and infection of the human placenta. APMIS. 2018;126(7):570-88.

11. Kaur J, Bathla SC. Regenerative potential of autologous plateletrich fibrin with and without amnion membrane in the treatment of grade-II furcation defects: a clinicoradiographic study. J Indian Soc Periodontol. 2018;22(3):235-42.

12. Murri MS, Moshirfar M, Birdsong OC, Ronquillo YC, Ding Y, Hoopes PC. Amniotic membrane extract and eye drops: a review of literature and clinical application. Clin Ophthalmol. 2018;12: $1105-12$.

13. Olaya-C M, Michael F, Fabian G, Silva JL, Bernal JE (2018) Role of VEGF in the differential growth between the fetal and placental ends of the umbilical cord. J Neonatal-Perinatal Med.

14. Otani T, Ochiai D, Masuda H, Abe Y, Fukutake M, Matsumoto T, et al. The neurorestorative effect of human amniotic fluid stem cells 
on the chronic phase of neonatal hypoxic-ischemic encephalopathy in mice. Pediatr Res. 2019;85(1):97-104.

15. Sane MS, Misra N, Quintanar NM, Jones CD, Mustafi SB. Biochemical characterization of pure dehydrated binate amniotic membrane: role of cytokines in the spotlight. Regen Med. 2018.

16. Marcus AJ, Woodbury D. Fetal stem cells from extra-embryonic tissues: do not discard. J Cell Mol Med. 2008;12(3):730-42.

17. Marcus AJ, Coyne TM, Black IB, Woodbury D. Fate of amnionderived stem cells transplanted to the fetal rat brain: migration, survival and differentiation. J Cell Mol Med. 2008;12(4):1256-64.

18. Maraldi T, Bertoni L, Riccio M, Zavatti M, Carnevale G, Resca E, et al. Human amniotic fluid stem cells: neural differentiation in vitro and in vivo. Cell Tissue Res. 2014;357(1):1-13.

19. Jezierski A, Rennie K, Zurakowski B, Ribecco-Lutkiewicz M, Haukenfrers J, et al. Neuroprotective effects of GDNF-expressing human amniotic fluid cells. Stem Cell Rev Rep. 2014;10(2):251-68.

20. Meng H, Li M, You F, Du J, Luo Z. Assessment of processed human amniotic membrane as a protective barrier in rat model of sciatic nerve injury. Neurosci Lett. 2011;496(1):48-53.

21. Sadraie SH, Parivar K, Arabi F, Moattari M, Kaka G, Mansouri K. Study of transected sciatic nerve repair by amniotic membrane with betamethasone in adult albino Wistar rats. Arch Iran Med. 2016;19(9):612-7.

22. Riccio M, Pangrazi PP, Parodi PC, Vaienti L, Marchesini A, et al. The amnion muscle combined graft (AMCG) conduits: a new alternative in the repair of wide substance loss of peripheral nerves. Microsurgery. 2014;34(8):616-22.

23. Riccio M, Marchesini A, Pugliese P, De Francesco F. Nerve repair and regeneration: biological tubulization limits and future perspectives. J Cell Physiol. 2018;234(4):3362-75.

24. Gupta A, Kedige SD, Jain K. Amnion and chorion membranes: potential stem cell reservoir with wide applications in periodontics. Int J Biomater. 2015;2015:274082.

25. Broughton BRS, Lim R, Arumugam TV, Drummond GR, Wallace EM, Sobey CG. Post-stroke inflammation and the potential efficacy of novel stem cell therapies: focus on amnion epithelial cells. Front Cell Neurosci. 2012;6:66

26. Phan TG, Ma H, Lim R, Sobey CG, Wallace EM. Phase 1 trial of amnion cell therapy for ischemic stroke. Front Neurol. 2018;9:198.

27. Liu T, Wu J, Huang Q, Hou Y, Jiang Z, et al. Human amniotic epithelial cells ameliorate behavioral dysfunction and reduce infarct size in the rat middle cerebral artery occlusion model. Shock. 2008;29(5):603-11.

28. Evans MA, Broughton BRS, Drummond GR, Ma H, Phan TG, et al. Amnion epithelial cells - a novel therapy for ischemic stroke? Neural Regen Res. 2018;13(8):1346-9.

29. Gong F, Wei Z, Jin W, Li H, Deng C, et al. The role of Schwann cells-like cells derived from human amniotic membrane mesenchymal stem cells transplantation in flap nerves regeneration. Zhongguo Xiu Fu Chong Jian Wai Ke Za Zhi. 2018:32(1):80-90.

30. Chen S-H, Wang J-J, Chen C-H, Chang H-K, Lin M-T, et al. Umbilical cord blood-derived CD $34^{+}$cells improve outcomes of traumatic brain injury in rats by stimulating angiogenesis and neurogenesis. Cell Transplant. 2014;23(8):959-79.

31. Zanier ER, Montinaro M, Vigano M, Villa P, Fumagalli S, Pischiutta F, et al. Human umbilical cord blood mesenchymal stem cells protect mice brain after trauma. Crit Care Med. 2011;39(11):2501-10.

32. Wasielewski B, Jensen A, Roth-Härer A, Dermietzel R, Meier C. Neuroglial activation and $\mathrm{Cx} 43$ expression are reduced upon transplantation of human umbilical cord blood cells after perinatal hypoxic-ischemic injury. Brain Res. 2012;1487:39-53.

33. Deng-Bryant Y, Chen Z, van der Merwe C, Liao Z, Dave JR, Rupp R, Shear DA, Tortella FC 2012. Long-term administration of amnion-derived cellular cytokine suspension promotes functional recovery in a model of penetrating ballistic-like brain injury. $\mathrm{J}$ Trauma Acute Care Surg 73(2 Suppl 1):S156-S164
34. Wassmer C-H, Berishvili E. Immunomodulatory properties of amniotic membrane derivatives and their potential in regenerative medicine. Curr Diab Rep. 2020;20(8):31. https://doi.org/10.1007/ s11892-020-01316-w.

35. Fenelon M, Etchebarne M, Siadous R, Grémare A, Durand M, Sentilhes L, Torres Y, Catros S, Gindraux F, L'Heureux N, Fricain J-C. Assessment of fresh and preserved amniotic membrane for guided bone regeneration in mice. J Biomed Mater Res A. 2020;108(10):2044-56.

36. Bacik L, Dhossche J, Ortega-Loayza AG, Funk T. Treatment of an ulcerated hemangioma with dehydrated human amnion/chorion membrane allograft. JAAD Case Reports. 2018;4(9):890-2.

37. Massee M, Chinn K, Lei J, Lim JJ, Young CS, Koob TJ. Dehydrated human amnion/chorion membrane regulates stem cell activity in vitro. J Biomed Mater Res Part B Appl Biomater. 2016;104(7):1495-503.

38. Lyons AB, Chipps LK, Moy RL, Herrmann JL. Dehydrated human amnion/chorion membrane allograft as an aid for wound healing in patients with full-thickness scalp defects after Mohs micrographic surgery. JAAD Case Reports. 2018;4(7):688-91.

39. Schlanser V, Dennis A, Ivkovic K, Joseph K, Kaminsky M, Messer $\mathrm{T}$, et al. Placenta to the rescue: limb salvage using dehydrated human amnion/chorion membrane. J Burn Care Res. 2018;39(6): $1048-52$.

40. Sousa DON, Dharia DOR, Mehta DOS, Marshall DOK, Siegel DOD. Endoscopic use of EpiFix-dehydrated human amnion/chorion membrane (dHACM) allograft in patients with gastric leak following sleeve gastrectomy. J Surg Case Rep. 2017, 2017;(9):rjx184.

41. Bianchi C, Cazzell S, Vayser D, Reyzelman AM, Dosluoglu H, Tovmassian $\mathrm{G}$, et al. A multicentre randomised controlled trial evaluating the efficacy of dehydrated human amnion/chorion membrane (EpiFix $\left.{ }^{\circledR}\right)$ allograft for the treatment of venous leg ulcers. Int Wound J. 2018;15(1):114-22.

42. Koob TJ, Rennert R, Zabek N, Massee M, Lim JJ, Temenoff JS, et al. Biological properties of dehydrated human amnion/chorion composite graft: implications for chronic wound healing. Int Wound J. 2013;10(5):493-500

43. Santema TB, Poyck PPC, Ubbink DT. Skin grafting and tissue replacement for treating foot ulcers in people with diabetes. Cochrane Database Syst Rev. 2016;2:CD011255.

44. Burkey B, Davis W, Glat PM. Porcine xenograft treatment of superficial partial-thickness burns in paediatric patients. J Wound Care. 2016;25(2):S10-5.

45. Swim MM, Albertario A, Iacobazzi D, Caputo M, Ghorbel MT. Amnion-based scaffold with enhanced strength and biocompatibility for in vivo vascular repair. Tissue Eng Part A. 2018.

46. Andonovska D, Dzokic G, Spasevska L, Trajkovska T, Popovska $\mathrm{K}$, et al. The advantages of the application of amnion membrane in the treatment of burns. Prilozi. 2008;29(1):183-98.

47. Muralidharan S, Gu J, Laub GW, Cichon R, Daloisio C, McGrath LB. A new biological membrane for pericardial closure. J Biomed Mater Res. 1991;25(10):1201-9.

48. Zmijewski M, Pietraszek A. The application of deep-frozen and radiation-sterilized human amnion as a biological dressing to prevent prolonged air leakage in thoracic surgery. Ann Transplant. 2005;10(3):17-20.

49. Sangwan VS, Burman S, Tejwani S, Mahesh SP, Murthy R. Amniotic membrane transplantation: a review of current indications in the management of ophthalmic disorders. Indian J Ophthalmol. 2007;55(4):251-60.

50. Peraka RP, Kalra P. Multilayered amniotic membrane transplantation in a case of chronic corneal fistula. BMJ Case Rep. 2020;13(9): e237369. https://doi.org/10.1136/bcr-2020-237369.

51. Walkden A. Amniotic membrane transplantation in ophthalmology: An updated perspective. Clin Ophthalmol. 2020;14:2057-72. https://doi.org/10.2147/OPTH.S208008. 
52. Tseng SCG. Evolution of amniotic membrane transplantation. Clin Exp Ophthalmol. 2007;35(2):109-10.

53. Tseng SCG, Espana EM, Kawakita T, Di Pascuale MA, Li W, et al. How does amniotic membrane work? Ocul Surf. 2004;2(3):177-87.

54. Waked N, El-Kazzi V. Amniotic membrane utilization in ophthalmological surgical procedures. J Med Liban. 2005;53(1):39-44.

55. De Rotth A. Statistical analysis of 1,000 consecutive new eye patients. Am J Ophthalmol. 1945;28:1329-34.

56. Sorsby A, Haythorne J, Reed H. Further experience with amniotic membrane grafts in caustic burns of the eye. Br J Ophthalmol. 1947;31(7):409-18.

57. Kim JC, Tseng SC. Transplantation of preserved human amniotic membrane for surface reconstruction in severely damaged rabbit corneas. Cornea. 1995;14(5):473-84.

58. Azuara-Blanco A, Pillai CT, Dua HS. Amniotic membrane transplantation for ocular surface reconstruction. Br J Ophthalmol. 1999;83(4):399-402.

59. Lee SH, Tseng SC. Amniotic membrane transplantation for persistent epithelial defects with ulceration. Am J Ophthalmol. 1997;123(3):303-12.

60. Letko E, Stechschulte SU, Kenyon KR, Sadeq N, Romero TR, Samson CM, Nguyen QD, Harper SL, Primack JD, Azar DT, Gruterich M, Dohlman CH, Baltatzis S, Foster CS 2001. Amniotic membrane inlay and overlay grafting for corneal epithelial defects and stromal ulcers. Arch Ophthalmol 119(5):659-663

61. Kim JS, Kim JC, Hahn TW, Park WC. Amniotic membrane transplantation in infectious corneal ulcer. Cornea. 2001;20(7):720-6.

62. Solomon A, Meller D, Prabhasawat P, John T, Espana EM, et al. Amniotic membrane grafts for nontraumatic corneal perforations, descemetoceles, and deep ulcers. Ophthalmology. 2002;109(4): 694-703.

63. Pires RT, Tseng SC, Prabhasawat P, Puangsricharern V, Maskin SL, et al. Amniotic membrane transplantation for symptomatic bullous keratopathy. Arch Ophthalmol. 1999;117(10):1291-7.

64. Anderson DF, Prabhasawat P, Alfonso E, Tseng SC. Amniotic membrane transplantation after the primary surgical management of band keratopathy. Cornea. 2001;20(4):354-61.

65. Gomes JAP, dos Santos MS, Cunha MC, Mascaro VLD, Barros J de N, de Sousa LB. Amniotic membrane transplantation for partial and total limbal stem cell deficiency secondary to chemical burn. Ophthalmology. 2003;110(3):466-73.

66. Uçakhan OO, Köklü G, Firat E. Nonpreserved human amniotic membrane transplantation in acute and chronic chemical eye injuries. Cornea. 2002;21(2):169-72.

67. Shimazaki J, Shinozaki N, Tsubota K. Transplantation of amniotic membrane and limbal autograft for patients with recurrent pterygium associated with symblepharon. Br J Ophthalmol. 1998;82(3):235-40.

68. Shimazaki J, Kosaka K, Shimmura S, Tsubota K. Amniotic membrane transplantation with conjunctival autograft for recurrent pterygium. Ophthalmology. 2003;110(1):119-24.

69. Tsubota K, Satake Y, Ohyama M, Toda I, Takano Y, et al. Surgical reconstruction of the ocular surface in advanced ocular cicatricial pemphigoid and Stevens-Johnson syndrome. Am J Ophthalmol. 1996;122(1):38-52.

70. Basu S, Ali H, Sangwan VS. Clinical outcomes of repeat autologous cultivated limbal epithelial transplantation for ocular surface burns. Am J Ophthalmol. 2012;153(4):643-50 650.e1.

71. Basu S, Mohan S, Bhalekar S, Singh V, Sangwan V. Simple limbal epithelial transplantation (SLET) in failed cultivated limbal epithelial transplantation (CLET) for unilateral chronic ocular burns. Br J Ophthalmol. 2018;102(12):1640-5.

72. Cheng AMS, Yin HY, Chen R, Tighe S, Sheha H, et al. Restoration of fornix tear reservoir in conjunctivochalasis with fornix reconstruction. Cornea. 2016;35(6):736-40.

73. Deihim T, Yazdanpanah G, Niknejad H. Different light transmittance of placental and reflected regions of human amniotic membrane that could be crucial for corneal tissue engineering. Cornea. 2016;35(7):997-1003.

74. Niknejad H, Yazdanpanah G, Kakavand M. Extract of fetal membrane would inhibit thrombosis and hemolysis. Med Hypotheses. 2015;85(2):197-202.

75. Niknejad H, Yazdanpanah G, Ahmadiani A. Induction of apoptosis, stimulation of cell-cycle arrest and inhibition of angiogenesis make human amnion-derived cells promising sources for cell therapy of cancer. Cell Tissue Res. 2016;363(3):599-608.

76. Tehrani FA, Ahmadiani A, Niknejad H. The effects of preservation procedures on antibacterial property of amniotic membrane. Cryobiology. 2013;67(3):293-8.

77. Tseng SC. Amniotic membrane transplantation for ocular surface reconstruction. Biosci Rep. 2001;21(4):481-9.

78. Okumura N, Sakamoto Y, Fujii K, Kitano J, Nakano S, et al. Rho kinase inhibitor enables cell-based therapy for corneal endothelial dysfunction. Sci Rep. 2016;6:26113.

79. Connon CJ, Nakamura T, Quantock AJ, Kinoshita S. The persistence of transplanted amniotic membrane in corneal stroma. Am J Ophthalmol. 2006;141(1):190-2.

80. Rahman I, Said DG, Maharajan VS, Dua HS. Amniotic membrane in ophthalmology: indications and limitations. Eye (Lond). 2009;23(10):1954-61.

81. Capeáns C, Piñeiro A, Pardo M, Sueiro-López C, Blanco MJ, et al. Amniotic membrane as support for human retinal pigment epithelium (RPE) cell growth. Acta Ophthalmol Scand. 2003;81(3):271-7.

82. Ohno-Matsui K, Mori K, Ichinose S, Sato T, Wang J, Shimada N, et al. In vitro and in vivo characterization of iris pigment epithelial cells cultured on amniotic membranes. Mol Vis. 2006;12:1022-32.

83. Kiilgaard JF, Scherfig E, Prause JU, la Cour M. Transplantation of amniotic membrane to the subretinal space in pigs. Stem Cells Int. 2012;2012:716968.

84. Zhu D, Jin X, Zhou J. Transplantation of amniotic membrane for choroidal hole to treat suprachoroidal silicone oil migration. Acta Ophthalmol. 2017;95(6):e522-3.

85. Laurent R, Nallet A, Obert L, Nicod L, Gindraux F. Storage and qualification of viable intact human amniotic graft and technology transfer to a tissue bank. Cell Tissue Bank. 2014;15(2):267-75. https://doi.org/10.1007/s10561-014-9437-x.

86. Silini AR, Cargnoni A, Magatti M, Pianta S, Parolini O. The long path of human placenta, and its derivatives, in regenerative medicine. Front Bioeng Biotechnol. 2015;3:162. https://doi.org/10. 3389/fbioe.2015.00162.

87. Caporossi T, Tartaro R, De Angelis L, Pacini B, Rizzo S. A human amniotic membrane plug to repair retinal detachment associated with large macular tear. Acta Ophthalmol. 2019;97(8):821-3.

88. Caporossi T, Tartaro R, Pacini B, De Angelis L, Rizzo S. DSAEKderived glider technique to introduce human amniotic membrane patch through small-gauge trocar for retinal pathologies. Acta Ophthalmol. 2020;98(4):e526-7.

89. Caporossi T, Pacini B, Bacherini D, Barca F, Faraldi F, Rizzo S. Human amniotic membrane plug to promote failed macular hole closure. Sci Rep. 2020;10(1):18264. https://doi.org/10.1038/ s41598-020-75292-2.

90. Parolini B, Grewal DS, Pinackatt SJ, Baldi A, Di Salvatore A, et al. 2018. Combined autologous transplantation of neurosensory retina, retinal pigment epithelium, and choroid free grafts. Retina (Philadelphia, Pa). 38 Suppl 1:S12-S22.

91. da Cruz L, Fynes K, Georgiadis O, Kerby J, Luo YH, Ahmado A, et al. Phase 1 clinical study of an embryonic stem cell-derived retinal pigment epithelium patch in age-related macular degeneration. Nat Biotechnol. 2018;36(4):328-37.

92. Abbasi-Kangevari M, Ghamari S-H, Safaeinejad F, Bahrami S, Niknejad H. Potential therapeutic features of human amniotic mesenchymal stem cells in multiple sclerosis: immunomodulation, inflammation suppression, angiogenesis promotion, oxidative stress 
inhibition, neurogenesis induction, MMPs regulation, and remyelination stimulation. Front Immunol. 2019;10:238. https:// doi.org/10.3389/fimmu.2019.00238.

93. Caporossi T, Pacini B, De Angelis L, Rizzo S. Amniotic membrane plug to promote chronic post-traumatic macular hole closure. Ophthalmic Surg Lasers Imaging Retina. 2019;51(1):50-2.

94. Huang B, Ding C, Zou Q, Lu J, Wang W, Li H. Human amniotic fluid mesenchymal stem cells improve ovarian function during physiological aging by resisting DNA damage. Front Pharmacol. 2020;11:272. https://doi.org/10.3389/fphar.2020.00272.
95. Lei J, Priddy LB, Lim JJ, Koob TJ. Dehydrated human amnion/ chorion membrane (dHACM) allografts as a therapy for orthopedic tissue repair. Tech Orthop. 2017;32(3):149-57. https://doi.org/10. 1097/BTO.0000000000000229.

Publisher's Note Springer Nature remains neutral with regard to jurisdictional claims in published maps and institutional affiliations. 